\title{
SUJETOS POLITITCOS Y CULTURA DE LA RESISTENCIA EN AMÉRICA LATINA: APUNTES PARA UN DEBATE
}

\section{POLITICAL SUBJECTS AND CULTURE RESISTANCE IN LATIN AMERICA: NOTES FOR A DEBATE}

\author{
Kirenia Caridad Saborit Valdés \\ Universidad de Camagüey, Camagüey, Cuba \\ kirenia.saborit@reduc.edu.cu
}

Palabras Clave: Subjetividad; representaciones sociales; prácticas políticas; actores políticos.

Keywords: Subjectivity; social representations; political practices; political actors.

Resumen: El presente trabajo se ubica en el campo de las investigaciones sobre la categoría sujeto político a partir de la emergencia en la actualidad de nuevos actores y fuerzas sociales que protagonizan procesos políticos diversos. Tiene como objetivo valorar la conformación de una cultura de resistencia en sujetos políticos en América Latina a partir de emociones, creencias y sentimientos que poseen los hombres en la acción política en situaciones adversas como: conflictos, confrontaciones y lucha política. La sistematización de referentes teóricos y los métodos: inducción-deducción, análisis-síntesis e histórico-lógico son la base metodológica de la presente investigación.

Abstract: The present work is located in the field of research on the subject political category from the emergence of new actors and social forces that are protagonists of diverse political processes. Its objective is to assess the conformation of a culture of resistance in political subjects in Latin America based on emotions, beliefs and feelings that men have in political action in adverse situations such as: conflicts, confrontations and political struggle. The systematization of theoretical references and the methods: inductiondeduction, analysis-synthesis and historical-logical are the methodological basis of the present investigation.

\section{l. Introducción}

Los profundos cambios, reformas y transformaciones que ocurren en el mundo contemporáneo acarrean la presencia de actores y fuerzas políticas que proyectan acciones de lucha y resistencia en la gama de espectros que envuelven a las sociedades. De ahí que, la búsqueda de soluciones a situaciones diversas principalmente en la arena 
política genera la emergencia del llamado sujeto político. Estos para Paredes (2009: 91-92) son

“(...) un tipo de sujetos sociales que despliegan su voluntad colectiva en base a acciones de politicidad, (...) en forma tal de presentar alternativas con un contenido emancipatorio, cuestionando/rupturando/ modificando las relaciones de poder existente".

La experiencia que viven los sujetos políticos en América Latina desde el siglo XX hasta nuestros días es cuestión indispensable para entender la dinámica y movilidad que existe en el escenario de la política o en torno al poder político, donde se devalan luchas de intereses, ansias de representatividad, aspiraciones que hacen que los actores políticos se reconstruyan como sujetos de cambio. Así, la diversidad de sujetos políticos en los países de la región reaparecen con un marcado contenido político. Tal es el caso de la clase obrera, trabajadora, sindicatos, movimientos sociales, partidos políticos, movimientos juveniles y feministas, organizaciones sociales, de masas, profesionales y políticas, grupos étnicos, entre otras formas sociales.

Las proyecciones, perspectivas y posiciones asumidas en el ejercicio de la política llevan a estos sujetos a pensar la elaboración de demandas sociopolíticas, la formación de identidades nacionales y la aparición de conflictos en el marco de las sociedades caracterizadas por la incidencia de las políticas neoliberales y la crisis estructural que vive el sistema internacional actual. En este contexto adquiere especial atención, las emociones más profundas respecto al lugar que les toca vivir, la resistencia de los pueblos oriundos y nacionales como conjuntos homogéneos portadores de una cultura propia y distintiva en la búsqueda de una integración social, los miedos, incertidumbres y frustraciones de fuerzas políticas que protagonizan procesos y situaciones como patrimonio simbólico y de praxis de la protesta social, (Zárate, 2015); insoslayable tanto en dimensión pasada, presente y futura.

El panorama actual sobe la importancia que asumen estos sujetos políticos en el desarrollo histórico social en relación con factores culturales, motivacionales, emocionales y psicológicos que conforman la subjetividad humana tiene fuerte base desarrollo en la obra de especialistas entre los que se destacan: (Rauber, 2004); (González, 2008); (Paredes, 2009); (Retamozo, 2010); (Machado, 2010); (Méndez, 2011); (Zemelman, 2011); (Díaz, 2012); (Agier, 2012); (Jiménez y Echeverri, 2013); (López, 2013); (Samaddar, 2014) y (Pérez, s.a.).

Unido a estos referentes se encuentran los estudios de (González, 2007); (Garcés y Pérez, 2011); (Prieto, 2014); (Zárate, 2015) y (Romero, s.f.) los que constituyen base metodológica de la presente investigación al incorporar constructos teóricos sobre la categoría cultura de resistencia, necesarios para comprender el sentir y las emociones humanas como parte de la identidad cultural de los hombres y mujeres en la práctica política.

Los estudios anteriores, pese a que reflejan acciones de resistencia y lucha política que se implementan durante varias décadas en la región Latinoamericana por movimientos sociales, líderes políticos, organizaciones, clases sociales, sectores poblacionales, no alcanzan a visualizar la totalidad de sentimientos que portan estos sujetos políticos como parte de la subjetividad. Esto lleva a la conformación de una cultura distintiva en la formación de identidades naciona- 
les desde lo diverso, autóctono, distintivo, legítimo y lo popular. De ahí que, en el presente artículo se realice una valoración sobre la conformación de una cultura de resistencia en sujetos políticos en América Latina con énfasis en estos elementos.

\section{Panorama actual}

\section{2.l. Algunas consideraciones sobre la cultura de resistencia}

La problemática del sujeto político en América Latina resulta cuestión de interés en la medida que los actores sociales y fuerzas políticas se descubren como protagonistas de los procesos con capacidad de llevar adelante la conducción de la vida pública a la vez que portan emociones en el accionar popular. Ello ocurre porque se produce un fuerte involucramiento de los sujetos históricos en la consecución de las más importantes esferas como: política, economía, educación, producción, servicios, salud, acceso a cargos públicos, infraestructura, asistencia social, seguridad pública, desarrollo cultural, derecho al trabajo entre otras áreas claves para el desarrollo social, donde comparten experiencias prácticas que despiertan los sentimientos más profundos en las relaciones de poder y dominación que experimentan o se les quiere imponer como ocurre en algunos casos.

En este proceso de conformación/reconformación de sí mismos los sujetos políticos desarrollan la llamada resistencia cultural, simbólica, económica y política como conjunto de ideas que originan múltiples contradicciones, miedos, desesperanzas, rechazos, fracasos, retrocesos, momentos de ruptura, lo cual se mantiene en construcción y movimiento en el decursar del tiempo.
En este sentido, las múltiples dimensiones o percepciones que existen en las investigaciones sociales de lo que significa resistencia política o cultural pasa por la interpretación de la manera en que los actores asumen enseñanzas de la propia vida basadas en los diálogos, formas de lucha política, representaciones sociales. Ello, unido a procesos espirituales donde convergen conmociones, vivencias y experiencias individuales y colectivas e ideales.

En tal sentido, las contribuciones de González (2007: 8), llevan a inferir como cultura de resistencia el proceso permanente en el espectro político, social, económico que permea diversos espacios de la vida. Afirma el autor,

"Es un proceso de elaboración ideológica transmitida como herencia a determinados agentes sociales que lo asumen en forma de rechazo o lo artificialmente impuesto, de asimilación de lo extraño cuando sea compatible con lo propio y, por consiguiente, de desarrollo cultural, de creación de lo nuevo por encima de lo heredado."

Otros autores destacan que la cultura de resistencia es un proceso complejo, largo en la historia caracterizado por la lucha contra toda dominación hegemónica, contra planes de absorción de los pueblos, frente al poderío simbólico y cultural de las sociedades en su conjunto. Afirma Prieto (2014: 1),

“(...) como algo en permanente choque contra lo que podríamos llamar cultura de la colonización, es decir, contra los empeños de quienes han querido sojuzgarnos, liquidar nuestra identidad y nuestra soberanía."

Es evidente que, la resistencia de los llamados sujetos políticos -que aún hoy es más fuerte por estar en el contexto de políticas mediatizadas- tiene intrínseca los valores populares, democráticos y nacionales. 
Para adentrarse en un análisis exhaustivo sobre la conformación de una cultura de resistencia en sujetos políticos en el contexto Latinoamericano es preciso delimitar aspectos de singular importancia como: emociones que legitiman la lucha política, enfrentamientos al poder hegemónico, rechazo a la dominación, desprecio por el colonialismo, cultura de la liberación, diversidad cultural, dependencia política y económica, enajenación política, acción práctica, concepciones ideológicas, valores, tradiciones revolucionarias, todos ellos presentes en los procesos que acometen los sujetos políticos

(...) en la búsqueda de un espacio real para construir una sociedad donde quepan todos." González (2007: 9).

En medio de una intensa lucha política e ideológica como la que viven los pueblos de América Latina los sujetos políticos están obligados a recurrir al análisis de sus emociones. Aunque los retos y desafíos que están por delante no se limitan puramente a respuesta emocionales hay que detenerse a repensar, valorar y argumentar la complejidad que implica la subjetividad humana más allá del devenir de la realidades, de los procesos, coyunturas y condicionantes históricas; importante para vincular la práctica y acción a los procesos psicológicos.

La cultura de resistencia se forma desde la práctica revolucionaria aunque particularmente se caracteriza por la intransigencia ante patrones y modelos culturales extranjeros que expresan relaciones hegemónicas de dominación e impiden la instauración de proyectos que respeten la diversidad cultural. Desde esta perspectiva se comparten experiencias, ideas y vivencias cotidianas que convocan a la acción contra la dominación, la explota- ción incluso, la violencia patriarcal. Entonces la cultura de resistencia se vuelve un espacio de compromiso ético, político con la justicia, la igualdad de oportunidades, los derechos humanos y las posibilidades de implicación de hombres y mujeres, apostando a la diversidad y la identidad múltiple de todos los actores protagonistas del cambio. Siguiendo los criterios de González (2007: 8)

“(...) Entender el proceso de la resistencia como búsqueda, como movimiento de ideas, es importante para comprender su alcance. En él se dan elementos de progreso y retroceso que originan múltiples contradicciones, por lo que su desarrollo se muestra muy controvertido y no del todo homogéneo."

La formación de la resistencia no significa para los actores o fuerzas políticas un camino fácil, lineal o sin contradicciones, todo lo contrario, se requiere en la lucha permanente renovación de todo lo que puede afectar el avance de los objetivos estratégicos. Una de las cuestiones claves de la correlación en toda resistencia es el reconocimiento a la acción consciente de los sujetos en la elaboración e implementación de estrategias para rechazar concepciones dogmáticas, posiciones de dominación o intentos de socavar la seguridad y tranquilidad de las sociedades. Desde esta perspectiva, es evidente que la vía para sostener toda forma o manifestación de resistencia es enfrentar los desafíos de manera progresiva y con plena conciencia en los intereses que se quieren alcanzar.

Por otra parte, la conformación de una cultura de resistencia pasa porque se ha privado al sujeto de su derecho de participar en las cuestiones políticas. Los criterios de Rauber (2001: 3) corroboran que,

"(...) A consecuencia de ello en el pueblo crecen sentimientos de rechazo, descon- 
fianza y desprecio hacia la política, los partidos y los políticos, que los sectores del poder tratan de guiar hacia el apoliticismo en aras de excluir a los sectores populares de la participación política, para implementar sus planes con la manifestaciones de oposición y resistencia."

Es preciso asumir la conformación de una cultura política e ideológica en América Latina que comprenda la elaboración de programas populares de transformación radical, la asunción de lo más revolucionario y radical del pensamiento de nacionalidad y la identidad como un enclave de resistencia de los distintos sectores, grupos, clases y toda forma social interesadas en las realidades.

La cultura de resistencia como expresión de la subjetividad humana, es resultante del proceso de socialización política que ejercen los individuos, que inicia en momentos históricos concretos marcados por situaciones hostiles y conflictuales a través de la cual los sujetos asimilan, comparten principios, actitudes, conductas, valores que le permiten participar con entusiasmo y activismo en la vida política de la sociedad.

En este caso, la cultura de resistencia tiene que ver con el contexto, el conocimiento socialmente construido y todos los espectros de la existencia humana. Al decir de Almeida (2009: 29),

“(...) Las maneras en que los diferentes actores sociales acceden a la realidad que los circunda, la forma en que la vivencian, reproducen y construyen, genera conocimientos y prácticas que están mediadas (...) por el momento histórico y el desarrollo alcanzado en las sociedades."

Es evidente que, en la cultura de resistencia está la clave para entender la historia de los pueblos, las tradiciones de lucha, los factores legitimadores de los diferentes procesos políticos y la esencia misma de toda subjetividad humana.

\section{Acción política}

\section{3.l. Conformación de cultura de la resistencia en sujetos políticos en América Latina}

Entre los sujetos políticos que en los últimos años en América Latina intentan visualizar su papel decisorio en el desarrollo económico y político en diversos países se encuentra la clase obrera y trabajadora. La participación política de estas en países como: Cuba, Venezuela, Chile, México, entre otros, se encamina a la recomposición del movimiento sindical, reestructuración de las llamadas centrales de trabajadores y al involucramiento en los Ilamados movimientos sociales, capaces de acometer acciones para mejorar las condiciones de trabajo de las personas y satisfacción de necesidades materiales como: aumentos salariales, mejoras de vida, crear las bases para reasignación de espacios laborales, estudio, producción de bienes materiales y servicios y sobre todo a la contribución en la toma de decisiones políticas.

En este proceso de consolidación de la participación política y dada las circunstancias, se reconstruye un nuevo sujeto político, como lo define Rauber (2004: 26)

“(...) un sujeto sociopolítico múltiple y diverso, unificado a través de un proceso de articulación (y rearticulación) orgánica que potencia el proceso de constitución de los actores sociopolíticos en sujeto popular $(\ldots)^{\prime \prime}$. 
A la vez que, constituye un sujeto portador de una subjetividad donde esta juega un rol fundamental en la construcción de representaciones sociales porque transmite modos de actuación, comportamientos y actitudes. Según (Knapp, Suárez y Mesa, 2003), es condición necesaria para esclarecer algunos aspectos de la dinámica en la determinación de conductas.

Este análisis permite destacar en la práctica sociopolítica el crecimiento individual de los participantes y la construcción colectiva del conocimiento de la realidad donde adquiere importancia la personalidad, el crecimiento individual y las actividades psíquicas a partir de los cuales, los hombres crean su propia imaginación y sus sistemas de creencias en base a las experiencias de vida y los significados de los sentimientos que portan en la vida política.

Como parte de las realidades del sujeto político está su subjetividad, la que se construye en un contexto social muy específico que tiene expresión en su pensamiento y se encuentra vinculada a las relaciones prácticas, comunicativas, socializadoras y emotivas. En este orden expone Díaz (2012: 59) que,

“(...) la emergencia de subjetividad, no es un hecho genético, por el contrario, es un acontecimiento socio-cultural (...) en él, juegan un papel importante como dispositivos que potencian ciertos sentidos subjetivos, los procesos de socialización, vehiculizados en las agencias socializadoras y encarnados en los agentes socializadores respectivos".

Ello lleva a pensar al sujeto político desde sus manifestaciones afectivas, conscientes, en un sistema de relaciones humanas que encuentra enclave el reconocimiento a la razón humana, la liberación, el decoro, la autonomía para establecer relaciones con el resto mundo exterior. Entonces, la conformación de una subjetividad transita por la resignificación de un pensamiento libertador, su enmarcación y concientización en torno a los procesos que percibe y la experiencia acumulada en el decursar del tiempo. Las contribuciones de Accossatto (2017: 220) en torno a la subjetividad del individuo así lo corroboran,

“(...) el comienzo de cualquier experiencia humana que busca su dignificación, se vincula con la emergencia de una subjetividad política necesaria para la realización de cualquier acción colectiva".

Sobre el involucramiento de la clase obrera en la región en las políticas públicas, estatales, económicas, culturales, se aprecia que se constituye como una fuerza política que concientiza el momento histórico y se proyecta la edificación de una nueva realidad, donde no solo la interpreta, además la vive desde la integración con el movimiento revolucionario de la época. En esta dirección, se convierte en un conglomerado organizado políticamente con fuerte base en la construcción de un proyecto para conducir la viabilidad hacia una sociedad más justa. Unido a ello defiende valores culturales propios que le permiten rechazar los intentos de extrapolación de modelos económicos, políticos y sociales a imperar en su nacionalidad. En este punto se forma una cultura de la resistencia, matizada en opinión de Romero (s.f: 1) por

"el desmontaje de la cultura de la dominación, introyectada en las personas y grupos mediante diversos canales de socialización, así como la construcción de una cultura emancipatoria sustentada en relaciones de equidad, solidaridad y justicia social, es, sin duda, uno de los sentidos y desafíos más urgentes (...)". 
Otro sujeto político importante en la región lo constituyen los partidos políticos sobre todo, aquellos que permanecen proponiendo programas y proyectos representativos de las necesidades y aspiraciones de las distintas clases de la sociedad. Estas organizaciones representativas del orden político y social se reconstruyen colectivamente sin perder de vista que cada hombre de manera individual responde a sus necesidades materiales, prácticas culturales, hábitos de vida que se conjugan en intereses colectivos. Este es el reto más inmediato que a entender de la autora, tienen por delante los partidos políticos en el continente, reconstruirse colectivamente para sí, en representación de intereses y deseos comunes.

En este orden señala Muñoz (2016: 98) que,

"(...) luchas históricas que se han dado en colectivos con capacidad de instalar en la agenda pública demandas novedosas, creando un "consenso crítico" y restando, muchas veces, obediencia al poder instituido."

Estas constituyen un desafío que debe sistematizarse. A ello se agrega que, los colectivos implican un sistema de relaciones, espacios y tiempos que los hacen complejos pero a la vez distintivos y variables.

Este sujeto político, entendido como colectivo de hombre de valores, convicciones, ideales, de posición activa ante la vida, con capacidad autocrítica, se encamina hoy hacia la constitución de una ciudadanía, una identidad nacional, cuan complejas resulten ser sus interrelaciones con componentes, factores o sujetos de su entorno social; Zemelman (2011: 2) defiende que,

“(...) no es posible pensar en ningún tipo de estructura social, económica o política, como tampoco cultural, si no es como resul- tado de la presencia de sujetos en complejas relaciones recíprocas en cuanto a tiempos y espacios; lo que implica tener que enfocar los procesos como construcciones que se van dando al compás de la capacidad de despliegue de los sujetos (...)".

La resistencia cultural significa para estas organizaciones la defensa de la autonomía local, territorial y nacional para conservar los resguardos indígenas, populares, identitarios a través de los cuales se contribuir la interpretación de la realidad y su diversidad. En tal sentido plantea Rivera (2010: 7)

"La actualidad de nuestras abigarradas ciudades no puede pensarse sin ese conjunto de desplazamientos territoriales que atraviesan todo tipo de fronteras (de países, oficios, costumbres, lenguajes, comidas, etc.). Es en ese ir y venir incesante donde se constituye la trama material de nuestra vida diaria."

Los partidos políticos constituidos como sujetos del cambio y la transformación expresan su activismo desde la conformación de un pensamiento nacionalista cuya concreción se hace evidente en el la gestación de situaciones revolucionaria y el desarrollo de luchas democráticas.

Los factores psicológicos intervienen en el conjunto de relaciones que establecen los hombres en correspondencia con el contexto histórico, el medio social, la cultura dominante y el conjunto de individuos presentes en la interacción social. A través de los mismos se miden comportamientos, actitudes, modos de actuación, lo que permite a la vez transmitir valores, costumbres, normas, principios, estilos y modelos de intervención social. De ahí que, la acción política de estos partidos se fundamente en procesos emocionales en los que tiene un lugar singular los 
aprendizajes culturales, la búsqueda de la unidad, las emociones respecto a la vida pública y política.

En el marco de este sistema de relaciones e interacción con lo social se construye una cultura de resistencia caracterizada por la práctica de firmeza política, ideológica, ética y radical tanto en pensamiento como acción en oposición a políticas e intereses hegemónicos frente a quienes intentan imponer políticas neoliberales. Como ejemplifica Prieto (2014: 1)

"Las guerras imperiales de saqueo han ido siempre acompañadas por la satanización de las víctimas, de los otros, de los calificados como bárbaros, y la cultura del colonizador trata de imponer en el pueblo dominado un sentimiento de inferioridad (...)".

\subsection{Acción-participación de movimientos sociales desde la cultura de resistencia}

Los movimientos sociales - como otros sujetos políticos - en la conformación de sus estrategias se acompañan de lo popular, lo democrático y lo colectivo con una fuerte incidencia en lo social para transformar valores, identidades y culturas que manifiestan historicidad, acción política y relaciones espaciales para la construcción de una alternativa de cambio. Por ello, una de las aristas que merece ser analizada a la luz de nuestros días es el matiz que adquiere la lucha de los movimientos sociales en la actualidad, una lucha que impulsa propuestas y alternativas propias para combatir el menosprecio por sentirse ubicados en una escala inferior en las exigencias con respecto a: salud, empleo, educación, salario, políticas públicas, equidad de género, igualdad de oportuni- dades, acceso a las políticas y representatividad en el sistema gubernamental. Incluye actividad comunicativa, valorativa, procesos cognitivos, relaciones afectivas y conductuales que expresan conciencia política y revolucionaria.

El Congreso de los Pueblos en Colombia por citar un ejemplo - se constituye como actor social y sujeto político conformado por movimientos sociales en un proceso convocado por el movimiento indígena. Cuyo reconocimiento es evidente dada la efectividad de las luchas y la permanencia en la movilización política. Dicho movimiento tiene una identificación con lo popular donde, enfatiza Ortiz (2016: 3)

" (...) se identifican organizaciones campesinas, indígenas, de comunidades negras, barriales, sindicales, de pensionados, de mujeres, de diversidad sexual, grupos juveniles y colectivos artísticos, grupos eclesiales de base, colectivos ecologistas, agencias de prensa alternativa y colectivos de educación popular".

Ello, en la representación de identidades colectivas populares. Para este autor, la colectividad es condición indispensable en la acción política y la emergencia de un horizonte de emancipación al considerar, el papel del hombre desde una forma de organización colectiva para hacer la política. Es a partir de esta condición que surgen formas de resistencia y descolonización así como la constitución de nuevas identidades políticas y rearticulación de acciones colectivas de sujetos oprimidos.

En esta lucha los movimientos sociales participan en la toma de decisiones o involucramiento en la vida pública, defienden o representan intereses propios como sector social con un grado de madurez y asunción diferente al resto de los sujetos sociales. Implica constituirse para sí 
mismo y para otros, defender los ideales democráticos y sociales que afectan a las grandes masas populares desde el mantenimiento de una lucha constante de intereses y aspiraciones propias en pos de mejorar la sociedad o el régimen político. Allí donde solo ellos aprecian, comparten y trasmiten sentimientos permanece un fuerte proceso de concientización donde interviene lo común y a través de lo cual se forma una cultura de resistencia basada en la eliminación de desigualdades sociales y la inclusión de las mayorías. Sustenta Zárate (2015: 67):

"Los movimientos sociales articulan estructuras de sentimientos, promueven una gama diversa de emociones y sensaciones hacia los oponentes, son también guerras de interpretaciones".

El Movimiento de Trabajadores sin Tierra de Brasil es paradigma en Latinoamérica en la conformación y desarrollo de una cultura de resistencia. Los objetivos se enmarcan en la lucha por la tierra, la reforma agraria y la transformación social en general. Entre las características que se derivan de su acción está la construcción de prácticas representativas y organizadas que persiguen cambiar la sociedad en la que viven cotidianamente. Se expande a los espacios que abarcan los llamados nuevos movimientos sociales: educación, comunicación, vivienda, trabajo, salud, reforma salarial, políticas públicas que beneficien a todos en la vida social. En un estudio sistematizado por Wrobel (2015: 95) sobre este movimiento se reconoce en la vida cotidiana la premura de los cambios políticos,

“(...) hay una clara conciencia de que, en última instancia, la tierra para las familias campesinas y la Reforma Agraria no podrán ser alcanzadas sin una transformación política profunda."
Otro estudio realizado por Moreira (2010) sobre movimientos populares y luchas sociales en Uruguay muestra los sentimientos de desesperanza y marginalización que sienten estas organizaciones. Durante varios años del presente siglo el desarrollo de los mismos está asociado al papel que desempeñan los propios partidos políticos en el país, fundamentalmente en la lucha por el perfeccionamiento del aparato institucional y la legalidad. Sin embargo, hoy esa lucha trasciende la dependencia de los movimientos sociales a los partidos políticos porque no reciben el apoyo que se requiere para constituirse como una coalición de izquierda importante.

Los movimientos sociales uruguayos manifiestan rechazo a la desigualdad social, al retroceso de la gestión estatal pero fundamentalmente a la representatividad que los partidos políticos ejercen. Como sujetos políticos que deben llegar a conformarse para la transformación de la sociedad se manifiestan ignorados y alejados, sobre todo en los escenarios de elaboración de políticas públicas. De manera contradictoria, el autor (Ibid, 299) expone,

"(...) contexto de crisis estatal y partidaria, especialmente de la izquierda, la misma tuvo efectos complejos y diferenciales sobre los movimientos sociales y sus capacidades de acción, en tanto les planteó oportunidades de desarrollo a la vez que condicionó fuertemente las mismas."

La realidad que refleja Uruguay hasta entonces evidencia que aún existe una fuerte dependencia de los movimientos sociales para llevar a cabo la acción política en la sociedad como fuerza conductora de marchas políticas, protestas y movilizaciones. De ahí la urgencia de reconstruirse para poder realizar este cometido con éxitos y cumplir según Jiménez y Echeverri (2013: 9) 
“(...) un papel fundamental en la reconstrucción de tejido social y en la constitución de sujetos, terrenos abandonados por los lugares que, en la realidad de los textos y de la academia, la realidad de papel, deberían cumplir el estado y el espacio de lo público."

Lo antes expuesto confirma que, las coaliciones populares tienen como necesidad revitalizar sus culturas sobre todo aquellos factores que se apegan a la política, a proyectos de vida colectivos, a construcción de sentidos y realidades comunes y lo cotidiano. En ese entramado de relaciones afectivas surge la acción colectiva unida a relaciones de identidad, modelos y proyectos culturales a través de los cuales se expresan creencias y simpatía; al mismo tiempo que se promueven relaciones para darle sentido a los fines y objetivos que se persiguen.

Un escenario importante como ámbito de expresión y actuación de sectores oprimidos, reprimidos, excluidos, discriminados, populares lo constituye la categoría pueblo, donde se configuran los sectores, capas y clases sociales como sujetos políticos. La identidad de los pueblo parte de su propia autonomía y conciencia nacional relacionada con hábitos, costumbres, tradiciones, estilos de vida, que le imprimen al hombre la experiencia y capacidad de acción y procesos identitarios. Acota Muñoz (2016: 98) afirma que

"El "pueblo" (a veces articulado a la democracia, otras no tanto) emergió como un exceso incontenible dentro de las coordenadas que organizaban la vida política frente a los que se presentaban como los verdaderos propietarios del poder de decisión vinculante."

Hoy, los pueblos entran en el escenario político en la disputa por la renovación de nuevos órdenes de dominación, donde pretenden articular proyectos de resistencias política, de lucha ideológica, instauración de una gobernabilidad estable y de alcance de objetivos democráticos en sus estructuras organizativas. Todo ello, como forma de enfrentamiento a quienes imprimen falta de credibilidad, confianza y autoridad para desarrollar políticas nacionales. Se trata como asegura Castilla (2008: 60)

“(...) de su realidad existencial y, por tanto, como espacio desde el cual desarrollar un proceso de educación emancipadora efectiva que busque lograr incidencias o repiques más universales. Este es otro elemento más que le otorga validez a esta propuesta, pues hemos visto que se afirma, cada vez con mayor consenso, (...)"

La historia de los pueblos originarios en Latinoamérica deja una experiencia amarga en la tradición de luchas. Una de las razones está en la rápida exterminación de la población aborigen en países como Cuba y en otros, donde todavía se trata de mitigar las características de estas culturas que aportan no solo elementos étnicos a la formación de los pueblos, a sus nacionalidades e identidades culturales; también a la defensa de ideales y sentimientos por la cultura que le dio origen. Ante la desesperanza que se expande en muchos países del continente, Gómez (2014: 25) manifiesta,

“(... la catástrofe demográfica que calló sobre el mundo indígena americano en los siglos XVI y XVII anuncia la modernidad europea y nos permite situar una característica clara del poder colonial ibérico: su poder colonial y el uso indiscriminado de la violencia militar como mecanismo de invasión y política."

De ahí, la necesidad de los pueblos oriundos de llegar a formarse como un sujeto político capaz de desplegarse con ideas 
y propuestas propias, de forma colectiva, en las decisiones que afectan a las sociedades, como conglomeraciones homogéneas que despiertan sentir común. Hoy más que nunca permanece el reto de defender lo autóctono, lo propio para erradicar el sentimiento de inferioridad, de barbarie y satanización que ha impuesto a nuestras culturas originarias el colonizador foráneo (Prieto, 2014).

Por su parte, los llamados sindicatos o centrales de trabajadores también desempeñan un papel significativo en la vida política y pública. Aunque muchas de las prácticas se limitan a reformas económicas y demandas para mejoras salariales o condiciones de trabajo, enfrentan en la actualidad las políticas de privatización neoliberales y su lucha tiene incidencia importante en la sociedad civil. Un elemento a señalar es que, la acción de los sindicatos en la arena política permite ganar espacio público para la instauración de determinadas políticas estatales: trabajo decoroso, acceso a políticas públicas, uso público de recursos naturales, derecho a la tierra, entre otros.

En este caso, la Central Única de Trabajadores de Chile como una de las agrupaciones que protagonizan las luchas laborales y sociopolíticas se dirige esencialmente a la organización de los trabajadores y defender intereses en función de mejorar el bienestar económico, social y cultural, (Lischetti, 2009). Sin embargo, es preciso organizar un proyecto de mayor alcance que abarque procesos ideológicos, procesos emancipatorios y resistencias políticas frente a los conflictos de manera que, amplíen los derechos y oportunidades de la clase obrera y trabajadora y aporte nuevas garantías democráticas, económicas, culturales, educativas y sociales en general creando condiciones para revertir las truncas históricas entre sectores populares y la política estatal.

\subsection{Estrategias y desafíos de los sujetos políticos desde la resistencia}

La pluralidad de sujetos políticos que coexisten en la región Latinoamericana tienen como reto contribuir a las transformaciones necesarias para el perfeccionamiento y la promoción de políticas públicas inclusivas y autónomas con espíritu constructivo, educativo y sensibilizado dentro de los marcos de una agenda centrada en el desarrollo soberano y democrático de las personas. Esto requiere de definición ideológica, significa adoptar una postura esencial y radicalmente crítica frente al conjunto del sistema de dominación sociopolítico y económico capitalista, sus modalidades históricas de aplicación y sus consecuencias, postura cuya gradación de intensidad crítica y de transformación estructural pueden ir en un continuum desde la tesis de la introducción de reformas parciales y graduales al sistema hasta, la tesis de la ruptura de éste. Como sustenta Paredes (2009: 93)

“(...) los sujetos políticos presentan ciertos elementos constituyentes que le permiten desplegar su politicidad, estos son: la identificación antagónica, la voluntad colectiva transformacional, las acciones rebeldes y los proyectos emancipatorios".

Por tanto, es pertinente trazar como desafío para los sindicatos, movimientos sociales, partidos políticos, la clase obrera organizada y centrales de trabajadores, continuar constituyéndose en el presente como la alternativa de las sociedades contemporáneas frentes a los desafíos del capitalismo, los efectos hostiles de la glo- 
balización neoliberal y las consecuencias de una crisis estructural del sistema mundial. Los distintos sujetos políticos desde la protesta ética, intelectual y cultural deben continuar reformando una cultura de resistencia que subyace como parte de la cultura política, reafirmando valores y tradiciones de luchas sociales que recoge en su diversidad la historia de formación y desarrollo de los obreros, trabajadores, artesanos, profesionales, campesinos e indígenas y otros, que suelen llamarle minorías por su condición social y su posición excluidas del sistema político.

Desde esta perspectiva, no solo se constituye un componente esencial de la cultura nacional y de la identidad propia de los pueblos o naciones, también contiene una visión del mundo y de la humanidad y sobre todo, es portadora de una ética que implica una moral cívica en que el valor de la consecuencia, del esfuerzo solidario y consciente por la libertad y bienestar de los más desposeídos, se acompaña con el apego irrestricto a la libertad y la justicia, a la búsqueda honrada de la igualdad, de la dignidad y la profunda aspiración a la primacía del ser humano sobre toda otra consideración.

Pese a los esfuerzos de los distintos sujetos políticos en la región Latinoamericana por crear una sociedad sin discriminaciones y exclusiones persisten desafíos que deben ser colegiados para alcanzar este fin. Entre los retos más urgentes a repensar por parte de la diversidad de sujetos políticos están:

- Aprovechar oportunamente el discurso político, la oratoria y el trabajo en colectivo como espacios de comprensión, de inteorización y concientización de la realidad para conducir correctamente el cambio a la nueva sociedad socialista.
- Involucrarse decisivamente en la toma de decisiones políticas desde una implicación colectiva que envuelva a todos los actores desde la política para construir una fuerza social alternativa.

- Crear nuevas políticas a la altura de los sujetos y actores sociales de estos tiempos, que permitan la articulación colectiva de todas las fuerzas verdaderamente revolucionarias.

- Reconstituirse los sujetos políticos como nuevos sujetos políticos capaces de enfrentar las nuevas luchas por la emancipación social.

- Llegar a conformar una cultura de resistencia política que garantice el papel protagónico de los nuevos sujetos políticos en la lucha frente a la crisis estructural del sistema internacional actual, el detrimento de los valores humanos, ante el crecimiento de tendencias neofascistas, la discriminación de género y ante la agresión mundial de la cultura del coloniaje.

- Reafirmar la cultura ideológica y política como vía para la emancipación social desde la conciencia de clase.

- Es necesario superar la concepción de organización y práctica revolucionara de los sujetos políticos y el conjunto de actores que engloba la sociedad, a medida que cada uno de estos se reconstruye como un sujeto popular.

La necesidad de que los sujetos políticos en el escenario Latinoamericano continúen aliándose entre ellos mismos es condición indispensable para transitar a nuevas formas de lucha política e ideológica ante la hegemonía extranjera y una garantía para seguir ejecutando cambios sociales que beneficien a la mayor parte de la sociedad. En este sentido, afirma Rauber (2006: 54) sobre el papel que 
desempeña los sujetos políticos y sus formas de articulación,

"(...) Estos actores conforman nuevas identidades y sentidos de pertenencia en la misma medida en que -en la lucha por la sobrevivencia y transformación de la realidad en que viven-, van desarrollando un crecimiento de conciencia y organización, es decir, en la medida en que van asumiéndose como protagonistas conscientes de su historia".

Hoy, se continúan redefiniendo nuevos sujetos con otras aspiraciones de lucha, con un grado de madurez diferente y con necesidades de construcción de lo social y lo político, donde juegan un papel fundamental los profesionales e intelectuales, capaces de analizar cada realidad local, inaugurando una nueva práctica participativa. En este sentido, se deben evaluar los aportes y limitaciones con el ánimo de impulsar los nuevos paradigmas nacidos de la idea de la Revolución, acorde con los tiempos actuales.

Los sujetos políticos deben definir claramente sus roles en el proceso de desarrollo sociopolítico y articular con mejores condiciones con el resto de los sujetos o formas sociales de organización para alcanzar un bien común. La constitución de tales aspiraciones está estrechamente asociada a la capacidad de los sujetos políticos para definir los espacios de su actuación política que deben pretender desarrollar en su accionar político.

\section{Conclusiones}

La metodología empleada en la investigación y el ejercicio de valoración de la acción de distintos sujetos políticos - con énfasis en movimientos sociales - en el empeño de conformar una cultura de resistencia conduce a reevaluar la im- portancia de la unidad entre los factores objetivo y subjetivo. Por ello, lo particular del estudio presentado radica en que, en el devenir histórico de los distintos sujetos políticos en América Latina interviene la dimensión emocional, actitudinal, psicológica, de representatividad como categorías de análisis de las luchas y las protestas; cuestión que en ocasiones resulta insuficiente en la interpretación de la realidad.

Lo anterior ayudó a corroborar que, la realidad latinoamericana en las condiciones actuales continúa incorporando a sectores poblacionales, organizaciones políticas, sociales y de masas, distintas clases sociales, a afirmarse y distinguirse como verdaderos sujetos políticos, a constituirse como sujetos de resistencia a escala global. Actores, fuerzas políticas o sujetos están en la reconstrucción de alianzas estratégicas destinadas a configurar un programa de lucha nacional en consonancia con las aspiraciones de la región, en correspondencia con intereses de las sociedades que desean la construcción de nuevos proyectos de vida más justos, equitativos y democráticos.

Sin embargo, no pueden deslindarse las limitaciones que presenta la actividad política, en algunos caso conducida por la falta de unidad para alcanzar un objetivo común; una sociedad de alternativas favorables para todos sus ciudadanos. La principal distinción consiste en que, el cimiento y el carácter de perdurabilidad de la lucha económica, política e ideológica tiene que hacerse sobre la base de lo común, lo autóctono y lo distintivo de cada nacionalidad que tiene expresión en las emociones que caracterizan la lucha, la resistencia en contextos represivos y los sentimientos que la distinguen.

Para las distintas formas de organización social -en especial los movimientos- es 
preciso articular la efervescencia de posibilidades, oportunidades y alternativas que conlleven a una concepción revolucionaria y de cambio radical. Las acciones políticas tratadas en este trabajo conforman importantes soportes para la comprensión de la realidad actual que requiere de perfeccionar toda forma de lucha en un contexto en que claro que el panorama Latinoamericano asiste a nuevas formas de politicidad que tienen como eje transversal las pasiones más profundas de sus actores políticos y la condición de vanguardia revolucionaria.

De cualquier manera, los sujetos políticos en América Latina demandan de una mirada diferente que comprendan el papel de las emociones que sienten los actores y fuerzas políticas involucradas en resistencias, lo que enfrentan situaciones de violencia, amenazas, represiones y acoso. Sobre todo, es fundamental en el análisis de la coyuntura y la conciencia de clase.

\section{Bibliografía}

Accossatto, R. (2017). "Sujetos políticos, dignidad y movilización. Aportes de Arturo Roig al estudio latinoamericano de los movimientos sociales y las identidades políticas". Revista de Ciencias Sociales, 4, (7), 213-234.

Agier. M. (2012). "Pensar el sujeto, descentrar la antropología". Revista Cuadernos de Antropología Social, 35, 9-27.

Almeida, Y. (2009). Género y Racialidad: Un estudio de Representaciones Sociales en el barrio "La Timba". Tesis de Maestría publicada, Cuba, Universidad de La Habana.

Castilla, C. (2008). Educación popularjuventud-participación. Una alianza posible. [en línea]. Recuperado el 20 de septiembre de 2018 de, http://bibliotecavirtual.clacso.org.ar/ar/libros/campus/ freire/07Castilla.pdf

Díaz, A. (2012). Devenir subjetividad política: un punto de referencia sobre el sujeto político. Disertación doctoral publicada en Ciencias Sociales. Niñez y juventud. Manizales (Colombia), Universidad de Manizales.

Garcés, R. y Pérez, E.D. (2011). "Rumba, identidad y cultura de resistencia: una iniciativa para el desarrollo comunitario en Caibarién". Revista académica del Observatorio Iberoamericano del Desarrollo Local y de la Economía Social, 5, (11), 1-17. Gómez, D. (2014). Calibán en cuestión. Aproximaciones teóricas y filosóficas desde nuestra América. Bogotá, Ed. Desde Abajo.

González, J. (2008). "Anatomía del Poder: Episteme y sujeto político en Michel Foucault". Revista Konvergencias Filosofía, 6,19, 1-16.

González, M.R. (2007). Cultura de la resistencia: una visión desde el zapatismo. [en línea]. Recuperado el 20 de septiembre de 2018 de, http://www.scielo.org. $\mathrm{mx} / \mathrm{scielo}$.php? script=sci_arttext\&pid=S 166580272003000200006\#aff1

Jiménez, E. y Echeverri, C. (2013). "Movimientos sociales: lugares de lucha y construcción de sujeto". Revista El ágora USB, 13, (1), 91-154.

Knapp, E., Suárez, M.C. y Mesa, M. (2003). "Aspectos teóricos y epistemológicos de la categoría representación social". Revista Cubana de Psicología, 20, (1), 23-34.

Lischetti, M. (2009). "Prácticas políticas laborales: ¿Movimientos sociales 0 lucha de clases?". Revista Theomai, 19, 25-30.

Londoño, D.P. (2003). El significado de la resistencia cultural. Ponencia presenta- 
da en Evento Colombia insiste en los derechos humanos, Bogotá, Colombia.

López, A. (2013). Spinoza: Razón y Poder. Un estudio sobre el sujeto ético y político en Spinoza. Disertación doctoral publicada en Filosofía. Madrid, Universidad Nacional de Educación a Distancia.

Machado, M.C. (2010). "Sujeto y resistencia". Revista Trabajo Social, 12, 47-53. Méndez, E.E. (2011). Sujeto político y política. Elementos para una ampliación de la mirada en torno a la constitución del sujeto y el espacio político. Tesis de Magíster en Filosofía con mención en Axiología y Filosofía Política, Universidad de Chile, Santiago, Chile.

Moreira, C. (2010). "Movimientos populares y luchas sociales en Uruguay". Revista Interseções, 12, (2), 283-300.

Muñoz, M.A. (2016). "Sujeto político, democracia y pueblo: Argentina y Bolivia frente al nuevo siglo". Revista Entramado, 24, 96-110.

Ortiz, A.M. (2016). El proceso de articulación y constitución del Congreso de los Pueblos como sujeto político en Colombia. Buenos Aires: Ed. CLACSO.

Paredes, J. (2009). Constitución de sujetos políticos. Elementos epistémicos y metodológicos para su estudio. Tesis de Magister en Estudios Sociales y Políticos Latinoamericanos, Universidad Alberto Hurtado, Chile.

Pérez, A. (s.a.) El nuevo sujeto histórico frente a los desafíos de la emancipación en América Latina. La Habana: Ed. Instituto Cubano de Filosofía.

Prieto, A. (2014). "La cultura de la resistencia: la experiencia cubana". [versión electrónica]. Revista de Cultura Cubana La Jiribilla, 12, (674):1.

Rauber, M.I. (2001). Actores sociales, luchas reivindicativas y politica popular. [en línea]. Recuperado el 29 de sep- tiembre de 2018 de, www.rebelion.org/ docs/4856.pdf

(2006). América Latina, movimientos sociales y representación política. La Paz. Ed Fundación Bolivariana para la Democracia Multipartidista.

(2004). Sujeto social, politico e histórico en Latinoamérica hoy. Razones para su re-articulación. Disertación doctoral publicada, Instituto de Filosofía, La Habana, Cuba.

Retamozo, M. (2010). "Sujetos políticos: teoría y epistemología". Revista Ciencia Ergo Sum, 18 (1) 81-89.

Rivera, S. (2010). Ch'ixinakax utxiwa. Una reflexión sobre prácticas y discursos descolonizadores. Buenos Aires, Ed Tinta Limón.

Romero, M.I. (s.f.). La identidad: un enclave de resistencia cultural. [en línea]. Recuperado el 20 de septiembre de 2018 de, https://revista.ecaminos.org/article/ la-identidad-un-enclave-de-resistenciacultural/

Samaddar, R. (2014). La emergencia del sujeto político. (Trads., C. Juaneda y J.M. Reynares). [s.I.]:[s.n.]. (Trabajo original publicado en 2009).

Wrobel, I. (2015). "El MST de Brasil y la construcción de un sistema educativo autogestionado". Revista de la Red Intercátedras de Historia de América Latina Contemporánea. 2, (3), 93-105.

Zárate, M.C. (2015). "Resistencias y movimientos sociales transnacionales". Revista Alteridades, 25, (50), 65-77.

Zemelman, H. (2011). "Sujeto y subjetividad: la problemática de las alternativas como construcción posible". Revista Polis, 27, 1-9. 